\title{
Betel-quid dependence and oral potentially malignant disorders in six Asian countries
}

\author{
Chien-Hung Lee, Albert Min-Shan Ko, Cheng-Fang Yen, Koung-Shing Chu, Yi-Jun Gao, \\ Saman Warnakulasuriya, Sunarjo, Salah Osman Ibrahim, Rosnah Binti Zain, Walter K. Patrick \\ and Ying-Chin Ko
}

\section{Background}

Despite gradual understanding of the multidimensional health consequences of betel-quid chewing, information on the effects of dependent use is scant.

\section{Aims \\ To investigate the 12-month prevalence patterns of betel- quid dependence in six Asian populations and the impact of this dependence on oral potentially malignant disorders (OPMD). \\ Method \\ A multistage random sample of 8922 participants was recruited from Taiwan, mainland China, Indonesia, Malaysia, Sri Lanka and Nepal. Participants were evaluated for betel- quid dependency using DSM-IV and ICD-10 criteria and assessed clinically for oral mucosal lesions.}

\section{Results}

The 12-month prevalence of dependence was 2.8-39.2\% across the six Asian samples, and 20.9-99.6\% of those who chewed betel-quid were betel-quid dependent. Men dominated the prevalence among the east Asian samples and women dominated the prevalence in south-east Asian samples. 'Time spent chewing' and 'craving' were the central dependence domains endorsed by the chinese and southern/south-east Asian samples respectively, whereas the Nepalese samples endorsed 'tolerance' and 'withdrawal'. Dependency was linked to age, gender, schooling years, drinking, smoking, tobacco-added betel-quid use and environmental accessibility of betel-quid. Compared with non-users, those with betel-quid dependency had higher pre-neoplastic risks (adjusted odds ratios 8.0-51.3) than people with non-dependent betel-quid use (adjusted odds ratio 4.5-5.9) in the six Asian populations.

\section{Conclusions}

By elucidating differences in domain-level symptoms of betelquid dependency and individual and environmental factors, this study draws attention to the population-level psychiatric problems of betel-quid chewing that undermine health consequences for OPMD in six Asian communities.

\section{Declaration of interest}

None.
Betel-quid, the fourth most frequently consumed psychoactive substance worldwide, is a masticatory mixture combining the areca nut, betel leaf, slaked lime and locally varied flavourings. ${ }^{1}$ According to estimates, at least $10 \%$ of the world population chew some variety of betel-quid. ${ }^{2}$ Studies of the chemical constituents have demonstrated that the areca nut contains $11-26 \%$ tannins and $0.15-0.67 \%$ alkaloids. ${ }^{3,4}$ Among these, arecoline (the nut's major alkaloid) has a chemical structure comparable to nicotine. ${ }^{3}$ The addictive properties of the areca nut have been recognised by the International Agency for Research on Cancer (IARC) since $1985,{ }^{5}$ but data are sparse on the syndromes of betel-quid dependence among those who chew this mixture and the prevalence of dependency in the general population. In 2004 the IARC concluded that betel-quid is carcinogenic to humans (group $1)^{6}$ and later it has been linked to early tumour onset and an increased risk of contracting upper aerodigestive malignancies. ${ }^{7-13}$ Furthermore, its prolonged use has been reported to increase the risk of chronic conditions such as cardiovascular disease, type 2 diabetes and chronic kidney disease and of adverse pregnancy outcomes such as low birthweight. ${ }^{1,14}$ Oral lichen planus, oral submucous fibrosis and oral leukoplakia are a group of oral potentially malignant disorders (OPMD) thought to be linked to the development of oral squamous cell carcinoma. Despite the gradual understanding of the multidimensional health consequences of chewing, little is actually known concerning the effects of dependent betel-quid use on this group of oral precancerous disorders.

In 2008 the Centre of Excellence for Environmental Medicine at Taiwan Kaohsiung Medical University and the World Health
Organization (WHO) Collaborating Centre for Oral Cancer and Precancer in the UK initiated the Asian Betel-quid Consortium (ABC) study. The consortium studied the intercountry effects of betel-quid use, health consequences of dependent use and methods of mobilising outreach actions for the prevention of oral disease. $^{1,15}$ The consortium study objectives were, first, to delineate the 12-month prevalence patterns of betel-quid dependence among six diverse Asian populations using DSM-IV and ICD-10 criteria for substance use disorder; ${ }^{16,17}$ second, to investigate country-dependent factors explaining such dependence; and third, to examine the prevalence and risk of OPMD associated with betel-quid dependency.

\section{Method}

\section{Study sample}

Six large research centres in east, southern and south-east Asia conducted this international study, including Kaohsiung Medical University (Taiwan), Central South University (mainland China), the University of Peradeniya (Sri Lanka), Kathmandu University (Nepal), the University of Malaya (Malaysia) and Airlangga University (Indonesia). To work towards a comparative framework, identical protocols and a standardised questionnaire were administered in all investigated communities. The ethical review committee from each research centre approved the study proposal. Participant recruitment started in January 2009 and concluded in February 2010. Written informed consent was obtained from all participants prior to data collection. Study 
populations included inhabitants of southern Taiwan, the Hunan province of mainland China, middle Nepal, the central province of Sri Lanka, the Selangor, Sabah and Sarawak states of Malaysia, north Sumatra, east Java, Bali, west Nusa Tenggara, south Sulawesi and the Papua provinces of Indonesia (see online Fig. DS1). The method is described elsewhere. ${ }^{1}$ Briefly, a multistage random sampling method was used to select representative samples from the civilian, non-institutionalised population (15 years and older) in each study community. The chosen study areas are detailed in online Table DS1. The number of participants recruited from each study centre ranged from 1002 to 2356, with a high response rate $(68-100 \%)$.

\section{Measures}

Data were collected using a standardised questionnaire adapted from WHO surveys and other nationwide prevalence studies.

\section{Sociodemographic characteristics}

Gender, age, ethnicity, marital status, educational level, occupation and socioeconomic status were recorded.

\section{Substance consumption}

Details of patterns of betel-quid, alcohol and tobacco use comprised types consumed, age at initial use, daily consumption, use frequency, years of substance use and achievement of abstinence.

\section{Dependency domains and determination}

Eight domains derived from module E (substance use disorders) of the Structured Clinical Interview for DSM-IV Axis I Disorders and from the Schedules for Clinical Assessment in Neuropsychiatry were used to measure DSM-IV and ICD-10 dependence. ${ }^{18,19}$ These domains were:

(a) tolerance;

(b) withdrawal;

(c) larger intake (betel-quid is chewed in larger amounts or for longer periods than intended);

(d) unsuccessful cut-down (unsuccessful efforts to reduce or control betel-quid use);

(e) time spent chewing (spending large amounts of time obtaining betel-quid or chewing it);

(f) given up activities (reduction in important social, occupational or recreational activities because of betel-quid use);

(g) continued despite problems (continued betel-quid chewing despite awareness of physical or psychological problems caused by this habit);

(h) craving (a strong desire or sense of compulsion to chew betelquid).

Betel-quid chewers were defined as people who had consumed at least one quid of any type of betel or areca nut product per day for a minimum of 6 months. Among them, a positive diagnosis of DSM-IV dependency required three or more of domains (a) to (g) presented in the 12 -month period preceding our interview. A positive diagnosis of ICD-10 dependency required at least three of domains (a) to (c), (e) and (g) or (h) presented in the past 12 months. Participants who met either DSM-IV or ICD-10 diagnostic criteria were defined as those experiencing any betel-quid dependency.

\section{Betel-quid accessibility}

Seven features of environmental accessibility, including easy availability, low cost, ready-made packaging, attractive packaging, aggressive marketing, advertisements for betel-quid and misleading advertisements, as well as three preventive activities (betel-quidrelated bans, statutory warnings and health education awareness programmes) were measured (online Table DS2).

\section{Data collection}

The questionnaire was written first in English and translated into the appropriate language or dialect for each study population. The questionnaires were back-translated into English to verify their validity. A principal investigator at each study centre organised a team of dentists and dental hygienists, medical officers, interviewers and data-recording clerks. Under the direction of the team's principal investigator, interviewers completed a training programme designed for data collection prior to conducting face-to-face interviews. Using portable dental lights for illumination and plane dental mirrors for soft tissue retraction, dental professionals who had completed standardised training for diagnosing OPMD performed oral cavity examinations. The location and symptoms of oral lesions were carefully inspected based on WHO clinical criteria. ${ }^{20}$

\section{Statistical analysis}

The data were first prepared by calculating complex sampling weights. Stata version 11 (for Windows) survey data statistical procedures were then implemented to accommodate the complex sampling design. Analyses were performed in three stages. First, point estimates for the prevalence rates, means and percentages regarding betel-quid dependency status from each study area were calculated. Second, polytomous logistic regression models were applied to weighted data in evaluations of the influence of demographic factors and betel-quid usage features on non-dependent and dependent chewing. This type of logistic regression model enables simultaneous comparisons of a categorical dependent outcome with more than two levels. Finally, a binary logistic regression was used to model the effects of non-dependent and dependent chewing on the presence of oral lichen planus, oral submucous fibrosis, oral leukoplakia and OPMD. The adjusted odds ratios of contracting OPMD associated with the DSM-IV and ICD-10 symptom count (measured in numbers of those satisfying DSM-IV and ICD-10 dependence domains) were calculated using area-combined data. Furthermore, we employed principal component analysis and biplot to illustrate the relationship between betel-quid dependency domains and six Asian populations.

\section{Results}

Selected sociodemographic characteristics of the sample are shown in Table DS1. Differences in age and gender distributions existed across the study areas. Taiwanese, mainland Chinese and Sri Lankan participants had higher education levels. These divergences were accounted for during interpopulation comparisons.

\section{Prevalences of betel-quid dependency and dependence symptoms}

The 12-month betel-quid dependency prevalence defined by either DSM-IV or ICD-10 criteria was found to be higher in 
Table 1 Prevalence rates of 12-month betel-quid dependence and distribution of dependence symptom domains

\begin{tabular}{|c|c|c|c|c|c|c|c|c|c|c|c|c|}
\hline & \multicolumn{2}{|c|}{ Taiwan } & \multicolumn{2}{|c|}{ Mainland China } & \multicolumn{2}{|c|}{ Malaysia } & \multicolumn{2}{|c|}{ Indonesia } & \multicolumn{2}{|c|}{ Nepal } & \multicolumn{2}{|c|}{ Sri Lanka } \\
\hline & $\begin{array}{c}\text { Men } \\
n=736\end{array}$ & $\begin{array}{l}\text { Women } \\
n=812\end{array}$ & $\begin{array}{c}\text { Men } \\
n=1225\end{array}$ & $\begin{array}{l}\text { Women } \\
n=1131\end{array}$ & $\begin{array}{c}\text { Men } \\
n=383\end{array}$ & $\begin{array}{l}\text { Women } \\
n=620\end{array}$ & $\begin{array}{c}\text { Men } \\
n=965\end{array}$ & $\begin{array}{l}\text { Women } \\
n=976\end{array}$ & $\begin{array}{c}\text { Men } \\
n=664\end{array}$ & $\begin{array}{l}\text { Women } \\
n=338\end{array}$ & $\begin{array}{c}\text { Men } \\
n=385\end{array}$ & $\begin{array}{l}\text { Women } \\
n=687\end{array}$ \\
\hline \multicolumn{13}{|l|}{ Population prevalence, \% } \\
\hline Current chewer & 10.7 & $2.5^{\star *}$ & 23.9 & $1.8^{\star *}$ & 9.8 & $29.5^{\star \star}$ & 12.0 & $46.8^{* *}$ & 43.6 & 34.9 & 18.0 & 13.5 \\
\hline \multicolumn{13}{|l|}{ Betel-quid dependency rate } \\
\hline DSM-IV criteria & 4.2 & $1.1^{* *}$ & 7.7 & $0.4^{* *}$ & 2.0 & $7.7 * *$ & 10.0 & $40.5^{\star *}$ & 43.5 & 34.5 & 3.8 & 2.5 \\
\hline ICD-10 criteria & 3.5 & $1.1^{*}$ & 6.0 & $0.3^{* *}$ & 4.8 & $11.9 * *$ & 5.5 & $34.4^{* *}$ & 39.8 & 33.6 & 4.3 & 2.5 \\
\hline Any criteria ${ }^{a}$ & 4.5 & $1.1^{* *}$ & 8.0 & $0.4^{\star *}$ & 5.2 & $12.2^{\star *}$ & 10.1 & $41.5^{* *}$ & 43.5 & 34.5 & 4.5 & 2.8 \\
\hline \multicolumn{13}{|l|}{$\begin{array}{l}\text { Age-specific prevalence } \\
\text { (any criteria) }\end{array}$} \\
\hline$\leqslant 30$ years & 2.9 & 0.0 & 10.9 & 0.2 & 0.9 & 0.0 & 0.9 & 15.4 & 46.0 & 28.7 & 0.5 & 0.0 \\
\hline $31-40$ years & 4.7 & 0.0 & 10.1 & 0.4 & 0.0 & 3.8 & 13.2 & 31.2 & 39.9 & 33.6 & 6.9 & 0.6 \\
\hline $41-50$ years & 4.9 & 1.8 & 7.9 & 1.0 & 11.9 & 22.9 & 12.4 & 55.9 & 41.5 & 46.5 & 14.4 & 4.0 \\
\hline$\geqslant 51$ years & 5.7 & 2.5 & 1.8 & 0.4 & 13.7 & 38.2 & 19.0 & 79.8 & 41.9 & 56.8 & 3.1 & 7.2 \\
\hline$P$ for linear trend & 0.288 & 0.008 & $<0.001$ & 0.533 & $<0.001$ & $<0.001$ & $<0.001$ & $<0.001$ & 0.642 & 0.048 & 0.038 & $<0.001$ \\
\hline \multirow{2}{*}{\multicolumn{13}{|c|}{$\begin{array}{l}\text { Betel-quid chewer group } \\
\text { Dependence symptom } \\
\text { domain in chewers, \% }\end{array}$}} \\
\hline & & & & & & & & & & & & \\
\hline Tolerance & 25.8 & 30.4 & 10.9 & 13.6 & 9.8 & 23.5 & 11.5 & 53.3 & 99.6 & 98.9 & 12.0 & 10.7 \\
\hline Withdrawal & 23.0 & 21.4 & 18.2 & 15.6 & 73.1 & 64.6 & 89.1 & 88.7 & 99.6 & 98.8 & 7.2 & 10.2 \\
\hline Larger intake & 25.0 & 21.3 & 31.9 & 21.5 & 10.6 & 26.7 & 7.4 & 35.5 & 0.0 & 0.0 & 40.8 & 17.0 \\
\hline Unsuccessful cut-down & 37.3 & 36.0 & 28.4 & 24.3 & 0.0 & 0.0 & 78.3 & 60.7 & 99.6 & 98.9 & 26.9 & 32.5 \\
\hline Time spent chewing & 60.7 & 59.8 & 49.3 & 43.3 & 20.4 & 18.8 & 13.7 & 19.9 & 0.0 & 0.0 & 18.8 & 11.5 \\
\hline Given up activities & 37.7 & 15.7 & 25.5 & 12.7 & 14.3 & 10.8 & 93.0 & 76.2 & 0.0 & 0.0 & 4.9 & 8.8 \\
\hline Continued despite problems & 30.6 & 22.7 & 31.2 & 21.5 & 42.5 & 13.7 & 43.6 & 62.9 & 91.3 & 96.2 & 15.8 & 18.5 \\
\hline Craving & 31.1 & 64.0 & 18.5 & 20.1 & 84.7 & 70.2 & 87.8 & 89.9 & 0.0 & 0.0 & 80.1 & 72.7 \\
\hline \multicolumn{13}{|l|}{ Betel-quid dependency rate, \% } \\
\hline DSM-IV criteria & 39.3 & 45.1 & 32.0 & 24.5 & 20.8 & 26.1 & 83.9 & 86.6 & 99.6 & 98.9 & 21.2 & 18.5 \\
\hline ICD-10 criteria & 32.8 & 45.1 & 24.9 & 15.4 & 48.8 & 40.4 & 46.3 & 73.6 & 91.3 & 96.2 & 23.9 & 18.6 \\
\hline Kappa $^{\text {b }}$ & $0.742^{\star *}$ & $1.000 * *$ & $0.779 * *$ & $0.708^{* *}$ & $0.381 * *$ & $0.659 * *$ & $0.389 * *$ & $0.367 * *$ & $0.211^{* *}$ & $0.488^{* *}$ & $0.901 * *$ & $0.803^{* *}$ \\
\hline Any criteria ${ }^{a}$ & 41.7 & 45.1 & 33.3 & 24.5 & 52.8 & 41.3 & 84.4 & 88.7 & 99.6 & 98.9 & 24.9 & 20.9 \\
\hline
\end{tabular}

men $(3.5-7.7 \%)$ than in women $(0.3-1.1 \%)$ in Taiwan and mainland China, and higher in women $(7.7-40.5 \%)$ than in men $(2.0-10.0 \%)$ in Malaysia and Indonesia (Table 1). The maximum and minimum prevalences of any betel-quid dependency occurred respectively in Nepal (39.2\%) and Taiwan (2.8\%; Fig. DS1). The prevalence of any betel-quid dependency was positively correlated with age in many male and female study groups $(P \leqslant 0.048$ for trend) but negatively correlated with age in Hunan male respondents $(P<0.001$ for trend). Among those who currently chewed betel-quid, the proportion of dependency was $20.9-33.3 \%$ in mainland China and Sri Lanka, $41.3-52.8 \%$ in Taiwan and Malaysia and $84.4-99.6 \%$ in Indonesia and Nepal. Two principal components were found to explain $70.6 \%$ of the variance of dependence symptoms in investigated populations (Fig. 1). The biplot revealed that among those who chewed betel-quid, dependency domains were more correlated within the six south and south-east Asian groups, within the four east Asian groups and within the two Nepalese groups. These three groups were clustered in the first, second and fourth quadrants. 'Craving' and 'time spent chewing' were the most important dependency domains for populations of Sri Lanka, Malaysia and Indonesia and of Taiwan and mainland China respectively, because their positions were nearest to the respective clusters. In contrast, 'tolerance' and 'withdrawal' were the major domains for the Nepalese population. In the three group clusters, $70.2-89.9 \%, 43.3-60.7 \%$ and $98.9-99.6 \%$ of participants who chewed betel-quid were found to have 'craving', 'time spent chewing' and 'tolerance' plus 'withdrawal' respectively (Table 1).

\section{Non-dependent and dependent chewing}

Table 2 shows the influence of sociodemographic factors and concomitant use of alcohol and tobacco on betel-quid dependency across various populations. Findings from Nepal were presented for dependent chewing only because the overwhelming majority of participants who chewed betel-quid were dependent users. In Malaysia, Indonesia and Sri Lanka, dependency was related to older age, but in mainland China it was related to younger age. Compared with those with 10 or more years of schooling, participants from Taiwan, Malaysia and Sri Lanka with 6 years of schooling or less had 3.4-4.8 and 3.1-27.2 times greater risks of becoming non-dependent and dependent chewers respectively. In the Sri Lankan sample, a heterogeneously higher risk of becoming dependent was observed (adjusted odds ratio (OR) 5.4). Those who drank alcohol were more likely to be dependent on betel-quid (adjusted OR 2.1-12.7), except in Indonesia. In Malaysia and Indonesia, tobacco smokers were less likely to have any betel-quid dependency than non-smokers (adjusted OR 0.04-0.3). The amount and frequency of betel-quid consumption were significant predictors of dependency among mainland Chinese, Malaysian, Indonesian and Sri Lankan chewers (adjusted OR 1.1-1.5 and 1.4-1.8 respectively). In the Sri Lankan samples, tobacco-added betel-quid created a 5.8-fold higher risk of dependency than tobacco-free betelquid, whereas in Hunan a family history of betel-quid use showed an appreciable influence on dependency (adjusted OR 2.6). 


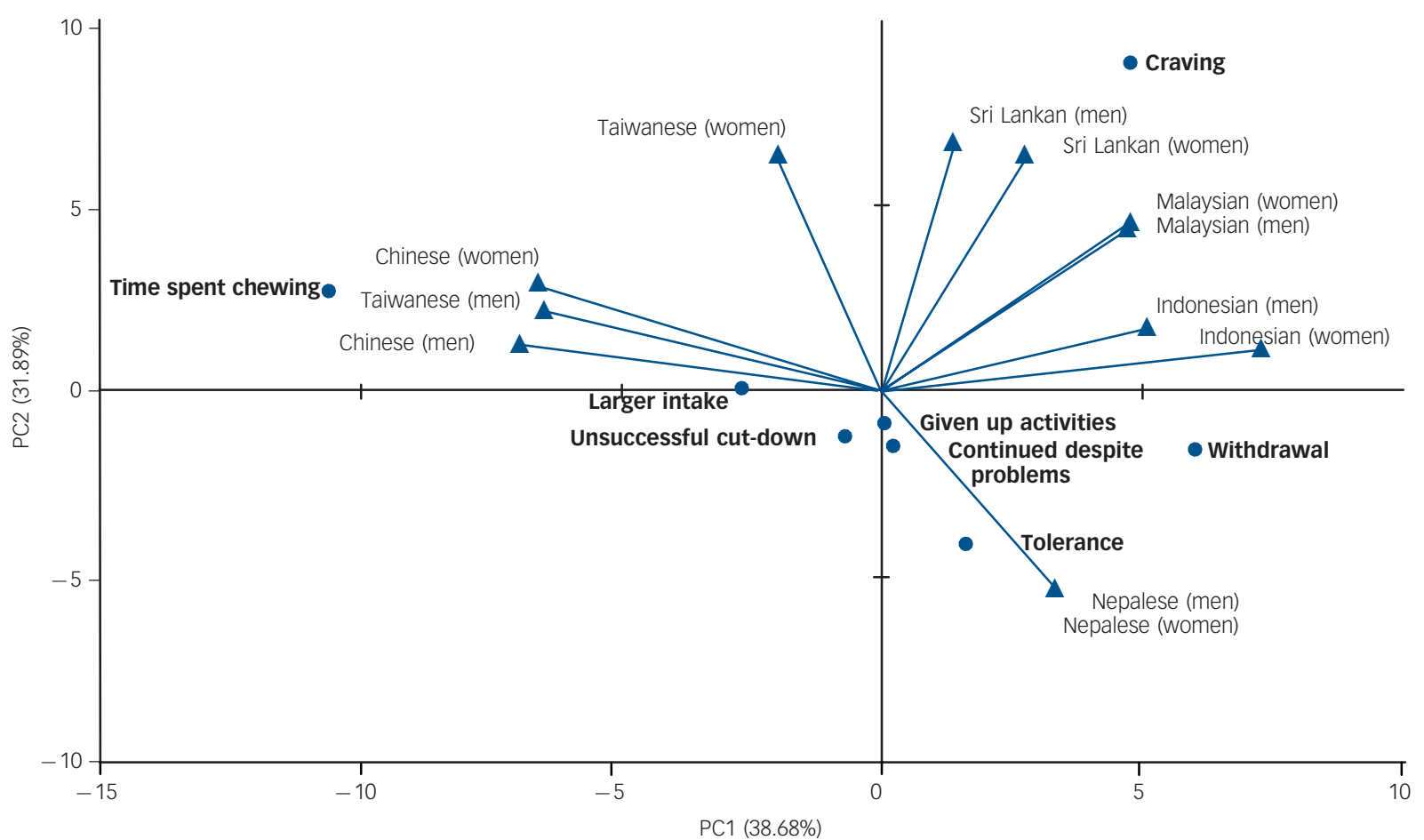

\section{Fig. 1 Principal component analysis and biplot of the betel-quid dependence symptoms $\times$ populations}

Circles denote the eight dependency domains and triangles denote the 12 study groups. The percentages indicate the amount of variance accounted for by principal components PC1 and PC2. Total explained variance from the first two components is $71 \%$. Among the populations who chewed betel-quid, dependency domains were more correlated within the six south and south-east Asian samples, within the four east Asian samples and within the two Nepalese samples. These three groups are clustered in the first, second and fourth quadrants respectively. Domains 'craving' and 'time spent chewing' were the most important dependency symptoms for Sri Lankan, Malaysian and Indonesian populations and for Taiwan and Hunan populations respectively. In contrast, the more biological domains of dependence, 'tolerance' and 'withdrawal', were the major dependency symptoms for Nepalese populations.

\section{Betel-quid accessibility and prevention}

Table 3 and online Tables DS2 and DS3 present an assessment of betel-quid approachability factors, including environmental accessibility and preventive activities. We found that all communities had features of easy availability, low price and ready-made packaging of betel-quid. Attractive and misleading advertisements for betel-quid were also observed in Hunan, and aggressive marketing of betel-quid products was active in Nepal. For preventive activities, several bans have been launched in Taiwan, such as prohibitions on spitting betel juice in the street and on the cultivation of areca nut palms. In Taiwan and Nepal, statutory warnings about the detrimental aspects of chewing are inscribed on betel-quid packets. Betel-quid was most easily available in the Hunan and Nepal communities (having six and five positive factors respectively), and no preventive activity existed in Hunan, Malaysia and Indonesia.

\section{Prevalence and risk of OPMD}

Table 4 shows the population prevalence and risks of OPMD categorised according to betel-quid use. Except in Malaysia, OPMD prevalence was higher in the dependent group (0.9$31.2 \%)$ than in the non-dependent user group (0.0-16.6\%). Compared with non-users, dependent participants had a greater OPMD risk (adjusted OR 2.5-51.5) than the non-dependent chewer group (adjusted OR 5.6-39.1). Using combined data from the six Asian populations, we evaluated the effect of the degree of betel-quid dependency on OPMD (Table 5). The prevalence of OPMD increased with the number of DSM-IV and ICD-10 dependence domains (both $P$ for trend <0.001). Overall, among participants who chewed betel-quid, those with five to seven DSM-IV domains had a 28- to 51-fold OPMD prevalence risk, whereas those with five or six ICD-10 domains had a 23-fold risk.

\section{Discussion}

Areca nuts have been chemically verified to contain several polyphenols (flavonols and tannins) and alkaloids (arecoline, arecaidine, guvacine and guvacoline) that possess stimulant and psychoactive effects. ${ }^{6}$ By raising adrenaline or noradrenaline levels, with the modulation of cholinergic and monoamine transmission, areca nut compounds exert neurobiological influences on the sympathetic and parasympathetic nervous systems. ${ }^{21-23}$ In human studies, prolonged use of betel-quid has been reported to cause tolerance and withdrawal syndromes (two central biological modules of dependence syndromes). ${ }^{24,25}$ Furthermore, among inhabitants of Papua New Guinea, areca nut psychosis was observed after sudden cessation of heavy betal-quid use. ${ }^{6}$ Among south-east Asian emigrants addicted to betel-quid, the substance has been persistently consumed even after migration to Western countries. ${ }^{26}$ The 'betel-mania' phenomenon found among emigrant chewers has been associated with the import of betelquid into ethnic enclaves. ${ }^{26}$ In this study we found that betel-quid dependency (DSM-IV prevalence 7.7-43.5\%) in specific groups, such as Hunan men, Malaysian women, and Indonesian and Nepalese samples, exceeded the reference DSM-IV prevalence of alcohol dependence reported in several national surveys worldwide $(1.2-4.4 \%) .^{27}$ 







\begin{tabular}{|c|c|c|c|c|c|c|}
\hline Factors & Taiwan & Mainland China & Malaysia & Indonesia & Nepal & Sri Lanka \\
\hline \multicolumn{7}{|l|}{ Environmental accessibility } \\
\hline Easy availability & Yes & Yes & Yes & Yes & Yes & Yes \\
\hline Low cost & Yes & Yes & Yes & Yes & Yes & Yes \\
\hline Ready-made packaging & Yes & Yes & Yes & No & Yes & Yes \\
\hline Attractive packaging & Yes & Yes & Yes & No & Yes & No \\
\hline Aggressive marketing & No & No & No & No & Yes & No \\
\hline $\mathrm{BQ}$ advertisement & No & Yes & No & No & No & No \\
\hline Misleading advertisement & No & Yes & No & No & No & No \\
\hline No. of factors for favourable BQ accessibility & 4 & 6 & 4 & 2 & 5 & 3 \\
\hline \multicolumn{7}{|l|}{ Preventive activity } \\
\hline BQ-related ban & Yes & No & No & No & No & No \\
\hline Statutory warning & Yes & No & No & No & Yes & No \\
\hline Health education awareness programmes & Yes & No & No & No & Yes & Yes \\
\hline No. of absent BQ usage prevention activities & 0 & 3 & 3 & 3 & 1 & 2 \\
\hline BQ dependence prevalence, $\%^{\mathrm{a}}$ & 2.8 & 4.4 & 8.6 & 26.2 & 39.2 & 3.4 \\
\hline
\end{tabular}

\section{Individual-level factors related to dependence}

In this survey, irrespective of the criteria used to define dependence, men dominated the betel-quid dependency prevalence among Taiwanese and mainland Chinese chewers and women dominated the prevalence in Malaysia and Indonesia. One previous study that examined factors affecting beginning and quitting chewing behaviours reported that Malaysian women are more likely to start and less likely to stop the chewing habit. ${ }^{28}$ These results emphasise that women who chew betel-quid should not be overlooked. In contrast to the social constraints imposed on tobacco and alcohol consumption, betel-quid chewing is publicly accepted, including use by women. ${ }^{29}$ Within certain Asian communities cigarette smoking is considered a male prerogative and betel-quid chewing a female habit, and women have learned the use of this substance primarily from their mothers and grandmothers. ${ }^{26}$

Among Hunan men the youngest age group was most affected by betel-quid dependency. Hunan is a southern province of China where betel-quid chewing is becoming prevalent. ${ }^{30}$ There, betelquid is consumed in dried husks of the areca fruit marinated with diverse flavoured ingredients. This style differs from usage patterns in other populations. Recent economic growth and heavier advertising have enhanced the popularity of betel-quid chewing in Hunan. One study showed that since the 1980s the number of those chewing has increased substantially. ${ }^{31}$ Young people have adopted this substance in its mint, cinnamon and orange flavours. Because China's betel-quid manufacturers and workshops have congregated in Xiangtan City in Hunan, ${ }^{31}$ easy availability, low price, attractive packaging and the lack of health risk warnings have formed the macro-environment that facilitates the development of dependency among those chewing betelquid.

We found that countries have diverse domain-level symptoms of betel-quid dependency. In Taiwan and Hunan, spending considerable time chewing betel-quid was the central indicator endorsed by men, and blue-collar workers were the major users. Because betel-quid chewing can help focus, keep users awake, heighten alertness and increase capacity for work, ${ }^{21,32}$ workers who chronically consumed betel-quid probably sought these pharmacological effects. ${ }^{33}$ We also observed that all Nepalese chewers used tobacco-added betel-quid, and relative to the other samples clustered more with 'tolerance' and 'withdrawal' symptoms (the more biology-associated domains of dependence). Preceding studies have demonstrated that nicotine-containing betel-quid is an addictive admixture that is likely to predispose people to dependent use of these substances. ${ }^{24}$ In Malaysia, Indonesia and Sri Lanka, 'craving' was the most common domain endorsed by participants with any betel-quid dependency. This suggests craving as a critical component for measuring betel-quid dependent use in south-east and south Asian communities. Because craving appears in ICD-10 but not in DSM-IV criteria, the DSM-5 working group incorporated craving into the new diagnostic schema for a substance use disorder. ${ }^{34}$ In a recent investigation conducted to determine whether craving fits with or improves the DSM-IV criteria set for alcohol use disorders, the inclusion of craving with the existing criteria better distinguished people with and without alcohol problems. ${ }^{35}$

A linear trend towards increased risk of betel-quid dependency with less schooling was observed for both men and women in Taiwan, Malaysia and Sri Lanka. This presents a challenging task for health education against betel-quid use because of its pervasive culture-derived features and favourable pharmacological effects. Some ethnic groups even treat betel-quid as an innocuous substance like coffee or tea. ${ }^{25}$ In one recent Sri Lankan survey, $76 \%$ of participants, primarily from lower socioeconomic groups, were unaware of any ill effects from areca nut use. ${ }^{36}$ In Indian communities, people were aware of higher cancer risks for gutka and tobacco use. However, awareness of detrimental health risks from betel-quid chewing remains limited. ${ }^{37}$

Alcohol drinking is a concomitant habit with betel-quid use in several cultures. ${ }^{1}$ We found that those who drank alcohol were more likely to be dependent on betel-quid in Taiwan, mainland China, Malaysia, Nepal and Sri Lanka (adjusted OR 2.1-12.7). Tobacco smoking was also found to predict betel-quid dependent use (adjusted OR 3.8-5.0) in the two Chinese populations. However, in Malaysia and Indonesia, where tobacco-added betel-quid is commonly used, smoking was associated with a lower probability of betel-quid dependency. Because tobaccoadded betel-quid chewing was inversely correlated with tobacco smoking $(r=-0.17$ and -0.57 for Malaysia and Indonesia respectively; both $P<0.001$ ), such betel-quid consumption may competitively diminish tobacco smoking in betel-quid dependency.

Chewing quantity and frequency were found to be the most significant factors for dependency, which was also observed in one Indian study as the chewing characteristics that contributed 


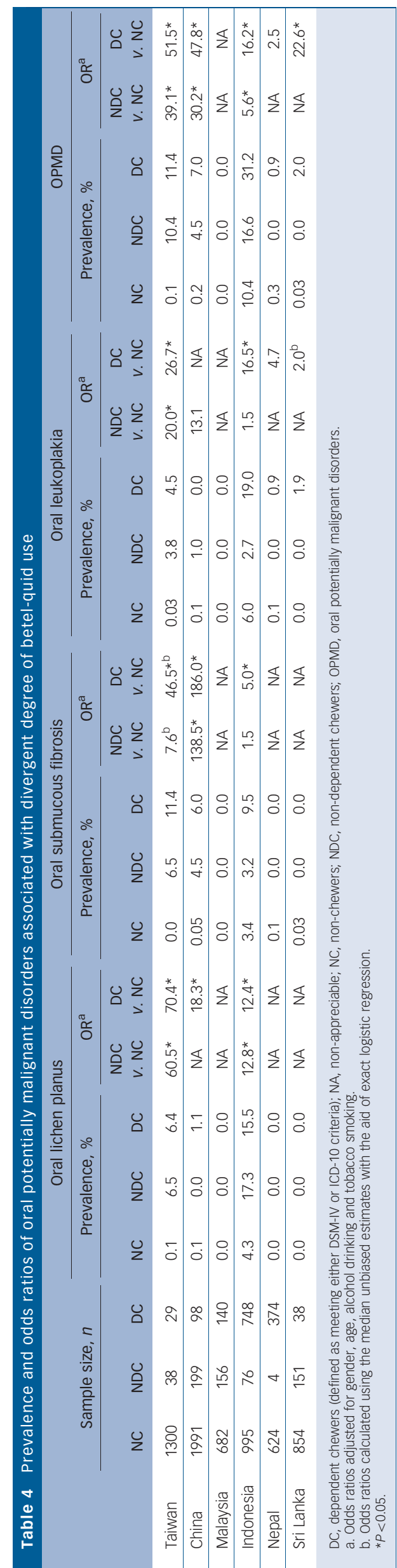

substantially to the DSM-IV criteria for areca nut dependence. ${ }^{24}$ For our Sri Lankan sample, using tobacco-added betel-quid conferred a higher risk of dependency than using tobacco-free mixtures. Such findings have been replicated ${ }^{24}$ and suggest that the addictive ingredient of tobacco (i.e. nicotine) may increase dependence on tobacco-added products. In Hunan, a family history of betel-quid use was another predictor of dependence. A previous study indicated that the father and grandfather are the most influential family members for inducing the first chewing habit in an adolescent. ${ }^{38}$ Family-based preventive programmes may be an effective approach to reducing betel-quid dependency in Hunan.

\section{Environmental factors and dependency}

Environmental access to betel-quid is a sociological concern. A report from India showed that betel-quid availability in a person's surroundings is closely associated with its use. ${ }^{39}$ In this study we observed five environmental promotion factors, such as aggressive marketing of betel-quid products in Nepalese communities. All Nepalese chewers were found to be users of tobacco-added products. The greater addictive properties of tobacco-added betel-quid, combined with its easy availability, may partially explain the high prevalence of betel-quid dependency (39\%) observed in Nepal.

In campaigns against chewing, the Taiwan government designated 3 December as Betel Quid Prevention Day, alluding to the 123-fold increase in oral cancer risk for betel-quid chewers who concurrently consumed alcohol and cigarettes. ${ }^{12}$ The outcome of the campaigns was a $21 \%$ reduction in betel-quid production in 2010 (130000 tonnes) relative to the year 2000 peak (165000 tonnes). ${ }^{40}$ These actions explain the lower prevalence of betel-quid dependency found in Taiwan. However, in places where such health promotions do not yet exist, such as Hunan, betelquid is widely marketed on television as a safe mouth freshener. In recent years, betel-quid has become one of the most important local industries, with an annual gross economic value approaching US $\$ 1.18$ billion. If current trends continue unabated, the availability of betel-quid will create a new generation of chewers among young people. ${ }^{1}$

\section{Betel-quid dependency and OPMD}

Most authorities agree that OPMD prevalence ranges from 1\% to $5 \%$, according to geographic region, population characteristics and patterns of substance use. ${ }^{41}$ The annual proportion of OPMD that develops into oral squamous cell carcinoma remains undetermined, but the current best estimates are $<0.1 \%$ for oral lichen planus, $0.5 \%$ for oral submucous fibrosis and $1 \%$ for oral leukoplakia. ${ }^{42}$ Evidence from previous studies shows that oral submucous fibrosis is a disorder not limited to the oral cavity; it may extend beyond the mouth to the oesophagus $(66 \%$ of patients with oral submucous fibrosis show histological abnormalities in the oesophagus). ${ }^{43}$ Consistent with the IARC report, ${ }^{6}$ we observed that people who chewed betel-quid had high prevalence rates of OPMD, especially if they were dependent users. In area-combined data, dependency levels and OPMD risk demonstrated dose-effect findings, regardless of the criteria used. Despite progress in molecular biology, no single biomarker has been identified to predict OPMD malignant transformations. ${ }^{42}$ Our results showed that the risk of OPMD in participants with non-dependent betel-quid use ( $0-2$ dependency domains) was 4.5-5.9 times greater than in the non-chewers group, increasing to 8.0-51.3 among those with dependency. These findings disclose the significance of considering people with betel-quid 
Table 5 Prevalence and adjusted odds ratios of oral potentially malignant disorders associated with the number satisfying DSM-IV and ICD-10 domains for betel-quid dependence: combined results from six Asian populations

\begin{tabular}{|c|c|c|c|}
\hline & Sample size, $n$ & Prevalence of OPMD, \% & $\mathrm{OR}^{\mathrm{a}}(95 \% \mathrm{Cl})$ \\
\hline Non-chewers & 6451 & 4.3 & 1.0 (reference) \\
\hline \multicolumn{4}{|l|}{ Current chewers } \\
\hline \multicolumn{4}{|l|}{ No. of DSM-IV domains } \\
\hline 0-2 (non-dependence) & 704 & 7.3 & $5.9(2.8-12.7)$ \\
\hline $3-4$ & 1040 & 16.9 & $8.0(4.5-14.3)$ \\
\hline $5-6$ & 280 & 42.4 & $27.5(10.8-69.6)$ \\
\hline 7 & 36 & 47.8 & $51.3(16.5-159.9)$ \\
\hline$P$ for linear trend & & $<0.001$ & $<0.001$ \\
\hline \multicolumn{4}{|l|}{ No. of ICD-10 domains } \\
\hline 0-2 (non-dependence) & 872 & 7.3 & $4.5(2.4-8.6)$ \\
\hline $3-4$ & 966 & 31.3 & $20.5(8.7-48.2)$ \\
\hline $5-6$ & 222 & 33.9 & $23.0(11.0-48.2)$ \\
\hline$P$ for linear trend & & $<0.001$ & $<0.001$ \\
\hline
\end{tabular}

dependency as an important screening target in the prevention and control of OPMD, and stress that those whose betel-quid use is non-dependent should not be neglected in oral examination programmes.

\section{Strengths and limitations}

Because betel-quid chewing was publicly accepted in all groups in the study, participants were comfortable revealing their usage; therefore, this may have diminished underreporting of the extent of betel-quid dependent use. Because of the cross-sectional nature of the results, our study presents only a snapshot of betel-quid dependency for the study populations. Furthermore, chewing practices and ingredients diverge by area. The findings in this survey should not be generalised to other areas within the respective countries. However, the research methodology and network might be extended to countries where betel-quid usage is common, such as Cambodia, Laos and Vietnam.

\section{Implications}

This study draws immediate attention to the population-level psychiatric problems of betel-quid chewing in six Asian communities where it is widely consumed. The findings disclose the role of sociodemographic factors, other substance use and environmental approachability in betel-quid dependency, and its health impact on OPMD. An understanding of these factors can facilitate implementation of health promotion measures and the adequate management of the OPMD burden resulting from betel-quid chewing.

\section{Funding}

This study was supported by a grant from the Centre of Excellence for Environmenta Medicine, Kaohsiung Medical University (KMU-EM-99-1-1), and the Taiwan National Science Council (NSC 99-2314-B-037-057-MY3).

\section{Acknowledgements}

We would like to thank Jennifer $\mathrm{Ko}$, and the staff of the Centre of Excellence for Environmental Medicine, for their great assistance in helping to organise the various centres' principal investigators.
Chien-Hung Lee, PhD, Department of Public Health, Kaohsiung Medical University, Taiwan; Albert Min-Shan Ko, MD, Leipzig School of Human Origins, Max Planck Institute for Evolutionary Anthropology, Germany; Cheng-Fang Yen, MD, PhD, Department of Psychiatry, Kaohsiung Medical University Hospital, Taiwan; Koung-Shing Chu, MD, Centre of Excellence for Environmental Medicine, Kaohsiung Medical University, Taiwan; Yi-Jun Gao, MD, Department of Stomatology, Second Xiangya Hospital, Central South University, China; Saman Warnakulasuriya, PhD, Department of Oral Medicine, King's College London, WHO Collaborating Centre for Oral Cancer and Precancer, UK; Sunarjo, MD, MS, Department of Public Health and Preventive Medicine, Airlangga University, Indonesia; Salah Osman Ibrahim, PhD, Department of Biomedicine, University of Bergen, Norway; Rosnah Binti Zain, PhD, Oral Cancer Research and Coordinating Centre, Faculty of Dentistry, University of Malaya, Malaysia; Walter K. Patrick, MD, PhD, Cancer Center, University of Hawaii Cancer Center, USA; Ying-Chin Ko, MD, PhD, Centre of Excellence for Environmental Medicine, Kaohsiung Medical University, and Graduate Institute of Clinical Medical Science, China Medical University, Taiwan

Correspondence: Professor Ying-Chin Ko, Centre of Excellence for Environmental Medicine, Kaohsiung Medical University, 100 Shih-Chuan First Road, Kaohsiung 807, Taiwan. Email: ycko@kmu.edu.tw

First received 21 Dec 2011, final revision 21 May 2012, accepted 14 Jun 2012

\section{References}

1 Lee $\mathrm{CH}$, Ko AM, Warnakulasuriya $\mathrm{S}$, Yin BL, Sunarjo, Zain RB, et al. Intercountry prevalences and practices of betel-quid use in south, southeast and eastern Asia regions and associated oral preneoplastic disorders: an international collaborative study by Asian betel-quid consortium of south and east Asia. Int J Cancer 2011; 129: 1741-51.

2 Gupta PC, Ray CS. Epidemiology of betel quid usage. Ann Acad Med Singapore 2004; 33: 31-6.

3 Lord GA, Lim CK, Warnakulasuriya S, Peters TJ. Chemical and analytical aspects of areca nut. Addict Biol 2002; 7: 99-102.

4 Changrani J, Gany F. Paan and Gutka in the United States: an emerging threat. J Immigr Health 2005; 7: 103-8.

5 International Agency for Research on Cancer. Tobacco Habits Other Than Smoking; Betel-quid and Areca-nut Chewing; and Some Related Nitrosamines. IARC Monographs on the Evaluation of Carcinogenic Risks to Humans vol 37. WHO, 1985

6 International Agency for Research on Cancer. Betel-quid and Areca-nut Chewing and Some Areca-nut-derived Nitrosamines. IARC Monographs on the Evaluation of Carcinogenic Risks to Humans vol 85. WHO, 2004.

7 Lee $\mathrm{CH}$, Lee KW, Fang FM, Wu DC, Shieh TY, Huang $\mathrm{HL}$, et al. The use of tobacco-free betel-quid in conjunction with alcohol/tobacco impacts early-onset age and carcinoma distribution for upper aerodigestive tract cancer. J Oral Pathol Med 2011; 40: 684-92.

8 Chiang SL, Chen PH, Lee CH, Ko AM, Lee KW, Lin YC, et al. Up-regulation of inflammatory signalings by areca nut extract and role of cyclooxygenase2-1195G > a polymorphism reveal risk of oral cancer. Cancer Res 2008; 68 : 8489-98. 
9 Lee KW, Kuo WR, Tsai SM, Wu DC, Wang WM, Fang FM, et al. Different impact from betel quid, alcohol and cigarette: risk factors for pharyngeal and laryngeal cancer. Int J Cancer 2005; 117: 831-6.

10 Lee $\mathrm{CH}$, Lee JM, Wu DC, Hsu HK, Kao EL, Huang HL, et al. Independent and combined effects of alcohol intake, tobacco smoking and betel quid chewing on the risk of esophageal cancer in Taiwan. Int J Cancer 2005; 113: 475-82.

11 Lee $\mathrm{CH}$, Ko YC, Huang HL, Chao YY, Tsai CC, Shieh TY, et al. The precance risk of betel quid chewing, tobacco use and alcohol consumption in oral leukoplakia and oral submucous fibrosis in southern Taiwan. $\mathrm{Br} J$ Cancer 2003; 88: 366-72.

12 Ko YC, Huang YL, Lee $\mathrm{CH}$, Chen MJ, Lin LM, Tsai CC. Betel quid chewing cigarette smoking and alcohol consumption related to oral cancer in Taiwan. J Oral Pathol Med 1995; 24: 450-3.

13 Lee $\mathrm{CH}$, Lee KW, Fang FM, Wu DC, Tsai SM, Chen $\mathrm{PH}$, et al. The neoplastic impact of tobacco-free betel-quid on the histological type and the anatomical site of aerodigestive tract cancers. Int J Cancer 2012; 131: E733-43.

14 Yang MS, Lee $\mathrm{CH}$, Chang SJ, Chung TC, Tsai EM, Ko AM, et al. The effect of maternal betel quid exposure during pregnancy on adverse birth outcomes among aborigines in Taiwan. Drug Alcohol Depend 2008; 95: 134-9.

15 Lee $\mathrm{CH}$, Ko AM, Warnakulasuriya S, Ling TY, Sunarjo, Rajapakse PS, et al. Population burden of betel quid abuse and its relation to oral premalignant disorders in South, Southeast, and East Asia: an Asian Betel-quid Consortium Study. Am J Public Health 2012; 102: e17-24.

16 American Psychiatric Association. Diagnostic and Statistical Manual of Mental Disorders (4th edn) (DSM-IV). APA, 1994.

17 World Health Organization. International Statistical Classification of Diseases and Related Health Problems (ICD-10). WHO, 1992.

18 First MB, Spitzer RL, Gibbon M, Williams JBW. Structured Clinical Interview for DSM-IV Axis I Disorders. American Psychiatric Press, 2005.

19 World Health Organization. Schedules for Clinical Assessment in Neuropsychiatry (SCAN). WHO, 1994

20 Kramer IR, Pindborg JJ, Bezroukov V, Infirri JS. Guide to epidemiology and diagnosis of oral mucosal diseases and conditions. World Health Organization. Community Dent Oral Epidemiol 1980; 8: 1-26.

21 Winstock A. Areca nut-abuse liability, dependence and public health. Addict Biol 2002; 7: 133-8.

22 Chu NS. Neurological aspects of areca and betel chewing. Addict Biol 2002 7: $111-4$.

23 Chen $\mathrm{PH}$, Tu HP, Wang SJ, Ko AM, Lee CP, Chiang TA, et al. Monoamine oxidase A variants are associated with heavy betel quid use. Addict Biol 2012; 17: 786-97.

24 Benegal V, Rajkumar RP, Muralidharan $\mathrm{K}$. Does areca nut use lead to dependence? Drug Alcohol Depend 2008; 97: 114-21.

25 Bhat SJ, Blank MD, Balster RL, Nichter M. Areca nut dependence among chewers in a South Indian community who do not also use tobacco. Addiction 2010; 105: 1303-10.

26 Pickwell SM, Schimelpfening S, Palinkas LA. 'Betelmania'. Betel quid chewing by Cambodian women in the United States and its potential health effects. West J Med 1994; 160: 326-30.
27 Teesson M, Hall W, Slade T, Mills K, Grove R, Mewton L, et al. Prevalence and correlates of DSM-IV alcohol abuse and dependence in Australia: findings of the 2007 National Survey of Mental Health and Wellbeing. Addiction 2010; 105: 2085-94.

28 Ghani WM, Razak IA, Yang YH, Talib NA, Ikeda N, Axell T, et al. Factors affecting commencement and cessation of betel quid chewing behaviour in Malaysian adults. BMC Public Health 2011; 11: 82.

29 Strickland SS. Anthropological perspectives on use of the areca nut. Addict Biol 2002; 7: 85-97.

30 Tang JG, Jian XF, Gao ML, Ling TY, Zhang KH. Epidemiological survey of oral submucous fibrosis in Xiangtan City, Hunan Province, China. Community Dent Oral Epidemiol 1997; 25: 177-80.

31 Zhang $X$, Reichart PA. A review of betel quid chewing, oral cancer and precancer in Mainland China. Oral Oncol 2007; 43: 424-30.

32 Chu NS. Effects of betel chewing on the central and autonomic nervous systems. J Biomed Sci 2001; 8: 229-36.

33 Ko YC, Chiang TA, Chang SJ, Hsieh SF. Prevalence of betel quid chewing habit in Taiwan and related sociodemographic factors. J Oral Pathol Med 1992; 21: 261-4.

34 O'Brien C. Addiction and dependence in DSM-V. Addiction 2011; 106: 866-7.

35 Keyes KM, Krueger RF, Grant BF, Hasin DS. Alcohol craving and the dimensionality of alcohol disorders. Psychol Med 2011; 41: 629-40.

36 Amarasinghe HK, Usgodaarachchi US, Johnson NW, Lalloo R, Warnakulasuriya S. Public awareness of oral cancer, of oral potentially malignant disorders and of their risk factors in some rural populations in Sri Lanka. Community Dent Oral Epidemiol 2010; 38: 540-8.

37 Gunaseelan R, Sankaralingam S, Ramesh S, Datta M. Areca nut use among rural residents of Sriperambudur Taluk: a qualitative study. Indian J Dent Res 2007; 18: 11-4.

38 Lu CT, Lan SJ, Hsieh CC, Yang MJ, Ko YC, Tsai CC, et al. Prevalence and characteristics of areca nut chewers among junior high school students in Changhua county, Taiwan. Community Dent Oral Epidemiol 1993; 21: 370-3.

39 Chaturvedi P. Areca nut or betel nut control is mandatory if India wants to reduce the burden of cancer especially cancer of the oral cavity. Int $J$ Head Neck Surg 2010; 1: 17-20.

40 Council of Agriculture. Yearly Report of Taiwan's Agriculture: 1979-2010 Council of Agriculture, Taiwan, 2012.

41 Napier SS, Speight PM. Natural history of potentially malignant oral lesions and conditions: an overview of the literature. J Oral Pathol Med 2008; 37: $1-10$.

42 Van der Waal I. Potentially malignant disorders of the oral and oropharyngeal mucosa; terminology, classification and present concepts of management. Oral Oncol 2009; 45: 317-23

43 Misra SP, Misra V, Dwivedi M, Gupta SC. Oesophageal subepithelial fibrosis: an extension of oral submucosal fibrosis. Postgrad Med J 1998; 74: 733-6. 